\title{
Editorial: CAR T-Cell Therapies in Hematologic Tumors
}

\author{
Marta Coscia ${ }^{1 *}$, Benedetto Bruno ${ }^{1}$ and Sattva Neelapu ${ }^{2}$ \\ ${ }^{1}$ University Division of Hematology, Azienda Ospedaliero-Universitaria Città della Salute e della Scienza di Torino, and \\ Department of Molecular Biotechnology and Health Sciences, University of Turin, Turin, Italy, ${ }^{2}$ Department of Lymphoma and \\ Myeloma, The University of Texas MD Anderson Cancer Center, Houston, TX, United States
}

Keywords: chimeric antigen receptors, CAR T-Cell therapies, chronic lymphocytic leukemia, B-cell non-Hodgkin lymphoma (B-NHL), multiple myeloma, acute myeloid leukemia (AML), acute lymphoblastic leukemia, CAR T-cell toxicities

\section{Editorial on the Research Topic}

\section{CAR T-Cell Therapies in Hematologic Tumors}

\section{INTRODUCTION}

Chimeric antigen receptors (CARs) are genetically constructed hybrid receptors that consist of a single-chain variable fragment ( $\mathrm{scFv}$ ) of a monoclonal antibody as the antigen-binding extracellular

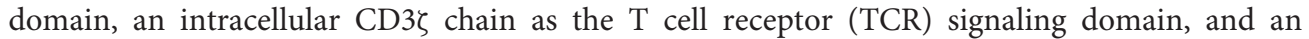
additional co-signaling domain, such as CD28 or $4-1 \mathrm{BB}$, to deliver co-stimulation $(1,2)$. The cytotoxic activity of CAR $\mathrm{T}$ cells is determined by antigen-binding to the scFv, which leads to phosphorylation of $\mathrm{CD} 3 \zeta$ and additional signaling cascades by co-stimulating domains (3). This mechanism recapitulates intracellular signaling following T-cell activation through the TCR complex, although, in an MHC-independent fashion.

Adoptive T-cell therapy was first clinically employed in 1988 by Rosenberg et al. using ex vivo expanded tumor-infiltrating T-cells in melanoma patients (4). At around the same time, the adoptive transfer of CAR-modified $\mathrm{T}$ cells was first proposed as an anti-tumor approach $(5,6)$. Early clinical trials of CAR T cells showed them to be a promising and safe approach, however, therapeutic efficacy was disappointing, likely due to the inability of CAR-modified $\mathrm{T}$ cells to expand and persist in vivo (7-9). The introduction of co-stimulatory molecules into the signaling domain of CARs greatly increased the potency and persistence of CAR T cells in preclinical studies and their subsequent evaluation in clinical settings demonstrated impressive benefits (10-12). Most successful clinical results have been observed with CD19-directed CAR $\mathrm{T}$ cells in B-cell lymphoproliferative disorders $(13,14)$, which led to the recent FDA and EMA approval of two CAR T-cell therapy products for the treatment of non-Hodgkin lymphomas (NHL) and/or acute lymphoblastic leukemia (ALL). However, in other hematological malignancies, several challenges still need to be overcome for the successful application of CAR T-cell therapies, including identifying target antigens and reversing repressive tumor microenvironments that hamper CAR T-cell function $(15,16)$.

This collection is comprised of a series of reviews providing a comprehensive overview of the current roles of CAR T-cell therapies in several hematological malignancies while also highlighting challenges for toxicity management and future development.

Greenbaum et al. review the role of CAR T-cell immunotherapy in ALL. They provide an overview of the promising results obtained in clinical trials that led to the approval of anti-CD19 CAR T cells for the treatment of relapsed/refractory pediatric patients with ALL. The authors highlight safety concerns as well as potential reasons that preclude durable responses in some 
patients as major obstacles to overcome the widespread use of this treatment. They also debate on the role of allogeneic hematopoietic stem cell transplantation as consolidation after CAR T-cell therapy, and present strategies currently under investigation for limiting resistance mechanisms, reducing systemic toxicities, and mitigating obstacles to manufacturing processes.

In their article, Vitale and Strati provide an overview of CAR T-cell therapy in the setting of B-cell NHL and chronic lymphocytic leukemia (CLL). They present results from trials investigating the efficacy and safety of two currently approved second-generation anti-CD19 CAR T-cell products (i.e., axicabtagene ciloleucel and tisagenlecleucel) and a third product (lisocabtagene maraleucel), which is expected to enter the market in 2020. The authors also provide a useful overview of real-world data, including results from special patient populations considered ineligible for pivotal clinical trials (e.g., patients with CNS disease and elderly subjects). Lastly, the review describes novel CAR T-cell-based strategies that are currently under evaluation and which aim to improve efficacy and reduce toxicity in the context of mature B-cell lymphoproliferative disorders.

Lobato et al., review the advances made with CAR T-cell therapy for multiple myeloma. They report results obtained with BCMA-targeted CAR T cells in heavily pretreated patients and outline the potential advantages and disadvantages of new candidate antigens, which are currently under investigation. The authors also provide a thorough description of novel strategies to improve persistence, potency, and trafficking of CAR T cells, such as the refinement of the CAR construct, the use of defined T-cell subpopulations, alternative sources for the production of CAR $\mathrm{T}$ cells, the combination approaches with immune modulatory agents, and the use of multi-antigen specific CAR T-cell products.

In their article, Mardiana and Gill provide a comprehensive overview of the current state of CAR T-cell therapy in acute myeloid leukemia (AML). They highlight barriers that limit the full therapeutic potential of this treatment strategy, in particular, the absence of a truly leukemia-specific cell-surface antigen. They also discuss other limitations of CAR T-cell therapy in AML, such as challenges in the manufacturing process due to the presence of leukemic blasts that negatively affect T-cell proliferation and the immunosuppressive mechanisms that diminish CAR Tcell efficacy. The authors also describe potential strategies to

\section{REFERENCES}

1. June CH, O'Connor RS, Kawalekar OU, Ghassemi S, Milone MC. CAR $\mathrm{T}$ cell immunotherapy for human cancer. Science. (2018) 359:13615. doi: 10.1126/science.aar6711

2. Sadelain M, Rivière I, Riddell S. Therapeutic T cell engineering. Nature. (2017) 545:423-31. doi: 10.1038/nature22395

3. Strati P, Neelapu SS. Chimeric Antigen Receptor-Engineered T cell therapy in lymphoma. Curr Oncol Rep. (2019) 21:38. doi: 10.1007/s11912-019-0789-z

4. Rosenberg SA, Packard BS, Aebersold PM, Solomon D, Topalian SL, Toy ST, et al. Use of tumor-infiltrating lymphocytes and interleukin-2 in the immunotherapy of patients with metastatic melanoma. A preliminary report. N Engl J Med. (1988) 319:1676-80. doi: 10.1056/NEJM198812223192527 overcome such limitations to produce CAR T cells with improved efficacy and tolerability.

CAR T-cell therapies are associated with a unique spectrum of toxicities that are not typically seen with traditional anticancer therapies (17). Sievers et al. in their review focus their attention on these clinical aspects particularly highlighting the role of advanced practice providers (APPs) as members of multidisciplinary care teams in the management of serious adverse events related to these adoptive cell therapies. The article also details approaches for the recognition and grading of the most common CAR T-cell therapy-related toxicities and the available decision support tools for APPs.

In summary, this collection of review articles provides a timely update on the progress made in the field of CAR T-cell therapies for hematologic malignancies, both in terms of the optimal strategies for the management of patients as well as novel products in the development to improve safety and efficacy. Despite the many challenges encountered in moving the field forward, great success has been observed in the last 20 years, leading to the commercial approval of CAR $\mathrm{T}$ cells for the treatment of B-cell lymphoproliferative disorders. Many investigations are ongoing to gain a better understanding of the biological mechanisms of toxicity and resistance. These studies on CAR T-cell biology will help develop next-generation strategies to further enhance the efficacy and reduce the toxicity of CAR-transduced cellular therapies, and to extend their applications to other hematological malignancies and solid tumors.

\section{AUTHOR CONTRIBUTIONS}

All authors listed have made a substantial, direct and intellectual contribution to the work, and approved it for publication.

\section{ACKNOWLEDGMENTS}

This was work was supported by an MD Anderson Cancer Center Support Grant P30 CA016672 from the National Institutes of Health and the MD Anderson Cancer Center B-cell Lymphoma Moonshot (SSN). MC would like to express her gratitude for the support given by Fondazione Cassa di Risparmio di Torino (CRT) while contributing to this collection of articles.
5. Gross G, Waks T, Eshhar Z. Expression of immunoglobulin-T-cell receptor chimeric molecules as functional receptors with antibody-type specificity. Proc Natl Acad Sci USA. (1989) 86:10024-8. doi: 10.1073/pnas.86.24.10024

6. Kuwana Y, Asakura Y, Utsunomiya N, Nakanishi M, Arata Y, Itoh S, et al. Expression of chimeric receptor composed of immunoglobulin-derived V regions and T-cell receptor-derived C regions. Biochem Biophys Res Commun. (1987) 149:960-8. doi: 10.1016/0006-291X(87)90502-X

7. Park JR, Digiusto DL, Slovak M, Wright C, Naranjo A, Wagner J, et al. Adoptive transfer of chimeric antigen receptor re-directed cytolytic $\mathrm{T}$ lymphocyte clones in patients with neuroblastoma. Mol Ther. (2007) 15:82533. doi: 10.1038/sj.mt.6300104

8. Till BG, Jensen MC, Wang J, Chen EY, Wood BL, Greisman HA, et al. Adoptive immunotherapy for indolent non-Hodgkin lymphoma and mantle 
cell lymphoma using genetically modified autologous CD20-specific T cells. Blood. (2008) 112:2261-71. doi: 10.1182/blood-2007-12-128843

9. Kershaw MH, Westwood JA, Parker LL, Wang G, Eshhar Z, Mavroukakis SA, et al. A phase I study on adoptive immunotherapy using gene-modified $\mathrm{T}$ cells for ovarian cancer. Clin Cancer Res. (2006) 12(20 Pt 1):610615. doi: 10.1158/1078-0432.CCR-06-1183

10. Krause A, Guo HF, Latouche JB, Tan C, Cheung NK, Sadelain M. Antigendependent CD28 signaling selectively enhances survival and proliferation in genetically modified activated human primary T lymphocytes. J Exp Med. (1998) 188:619-26. doi: 10.1084/jem.188.4.619

11. Maher J, Brentjens RJ, Gunset G, Rivière I, Sadelain M. Human T-lymphocyte cytotoxicity and proliferation directed by a single chimeric TCRzeta /CD28 receptor. Nat Biotechnol. (2002) 20:70-5. doi: 10.1038/nbt0102-70

12. Imai C, Mihara K, Andreansky M, Nicholson IC, Pui CH, Geiger TL, Campana D. Chimeric receptors with $4-1 \mathrm{BB}$ signaling capacity provoke potent cytotoxicity against acute lymphoblastic leukemia. Leukemia. (2004) 18:676-84. doi: 10.1038/sj.leu.2403302

13. Neelapu SS, Locke FL, Bartlett NL, Lekakis LJ, Miklos DB, Jacobson CA, et al. Axicabtagene ciloleucel CAR T-cell therapy in refractory large B-cell lymphoma. N Engl J Med. (2017) 377:2531-44. doi: 10.1056/NEJMoa1707447

14. Maude SL, Laetsch TW, Buechner J, Rives S, Boyer M. Tisagenlecleucel in children and young adults with B-cell lymphoblastic leukemia. $N$ Engl J Med. (2018) 378:439-48. doi: 10.1056/NEJMoa170 9866

15. Coscia M, Vitale C, Cerrano M, Maffini E, Giaccone L, Boccadoro M, et al. Adoptive immunotherapy with CAR modified $\mathrm{T}$ cells in cancer: current landscape and future perspectives. Front Biosci. (2019) 24:1284315. doi: $10.2741 / 4780$
16. Cerrano M, Ruella M, Perales MA, Vitale C, Faraci DG, Giaccone $\mathrm{L}$, et al. The advent of CAR T-cell therapy for lymphoproliferative neoplasms: integrating research into clinical practice. Front Immunol. (2020) 11:888. doi: $10.3389 /$ fimmu.2020.00888

17. Neelapu SS, Tummala S, Kebriaei P, Wierda W, Gutierrez C, Locke FL, et al. Chimeric antigen receptor T-cell therapy assessment and management of toxicities. Nat Rev Clin Oncol. (2018) 15:47-62. doi: 10.1038/nrclinonc.2017.148

Conflict of Interest: MC received Honoraria from Janssen, Gilead, Abbvie, Shire, and research support from Janssen and Karyopharm Therapeutics. BB received Honoraria from Gilead, Pfizer, Thermofisher, Jazz Pharma, Novartis, Janssen, and research support from Janssen. SN served as a Consultant or Advisory Board member for Kite, a Gilead Company, Merck, Bristol-Myers Squibb, Novartis, Celgene, Pfizer, Allogene Therapeutics, Cell Medica/Kuur, Incyte, Precision Biosciences, Legend Biotech, Adicet Bio, Calibr, and Unum Therapeutics; received research support from Kite, a Gilead Company, Bristol-Myers Squibb, Merck, Poseida, Cellectis, Celgene, Karus Therapeutics, Unum Therapeutics, Allogene Therapeutics, Precision Biosciences, and Acerta; received royalties from Takeda Pharmaceuticals, and has intellectual property related to cell therapy.

Copyright (C) 2020 Coscia, Bruno and Neelapu. This is an open-access article distributed under the terms of the Creative Commons Attribution License (CC BY). The use, distribution or reproduction in other forums is permitted, provided the original author(s) and the copyright owner(s) are credited and that the original publication in this journal is cited, in accordance with accepted academic practice. No use, distribution or reproduction is permitted which does not comply with these terms. 